\title{
ANALISA TEBAL PERKERASAN LENTUR PADA RENCANA PENINGKATAN JALAN RUAS LEGUNDI - PERTIGAAN BUNDER
}

\author{
Fandra Andriansyah $\mathrm{P}^{* 1}$, Sigit Winarto ${ }^{2}$, Yosef Cahyo $\mathrm{SP}^{3}$, Agata Iwan Candra ${ }^{4}$ \\ ${ }^{1,2,3}$ Fakultas Teknik, Universitas Kadiri. \\ e-mail:*1 fandraandriansyah12@gmail.com,2sigit.winarto@unik-kediri.ac.id, \\ 3yosef.cs@unik-kediri.ac.id, ${ }^{4}$ iwan_candra@unik-kediri.ac.id.
}

\begin{abstract}
The research is Analysis of Flexible Pavement Thickness in the Plan for Improvement of Legundi Road Section - Bunder KM.5 + 700 to $13+700$ STA. $0+000$ to $4+000$ which comprised the road geometrics, flexible pavement depth completed with the budgeting. A topographic map was employed to make a geometric design. Traffic data of 2018, rainfall data of 2018, and California Bearing Ratio (CBR) data were needed to design the flexible pavement depth. The basic itemized cost of wages, materials, tools, and work itemized cost from General Work BinaMarga of East Java Province Division IV (Surabaya, Gresik, Sidoarjo, Mojokerto, Jombang) were needed to find out the budget. Chosen alternative flexible pavement depth of $10 \mathrm{~cm}$ asphalt-concrete MS 744 surface, $20 \mathrm{~cm}$ Cement Tread Base (CTB) base, and $50 \mathrm{~cm}$ sandaggregate class A (CBR 70) sub-base.The calculations result in PI 01 Full-Circle bend and PI 02 FullCircle; at IDR 14.745.341.000.
\end{abstract}

Keywords: Component Analysis Method, Flexible Pavement, Geometric, Budget Plan

\begin{abstract}
Abstrak
Penelitian ini adalah melakukan Analisa Tebal Perkerasan Lentur Pada Rencana Peningkatan Jalan Ruas Legundi - Pertigaan Bunder KM.5+700 s/d 13+700 STA. 0+000 s/d 4+000 yang bertujuan untuk menghitung tebal perkerasan lentur jalan, menghitung geometric jalan dan rencana anggaran biaya proyek. Peta topografi sebagai dasar untuk merencanakan geometric jalan. Data lalu lintas tahun 2018, data curah hujan tahun 2018, data California Bearing Ratio (CBR) untuk merencanakan tebal perkerasan lenturjalan. Data Harga Satuan Dasar upah, bahan, dan alat serta Harga Satuan Pekerjaan dari Departemen Pekerjaan Umum Bina Marga Jatim kelompok IV (Surabaya, Gresik, Sidoarjo, Mojokerto, Jombang) digunakan untuk perhitungan Rencana Anggaran Biaya. Berdasarkan perhitungan didapatkan tebal perkerasan lentur alternative terpilih untuk surface $10 \mathrm{~cm}$ laston MS 744, base $20 \mathrm{~cm}$ Cement Tread Base (CTB), serta sub base $50 \mathrm{~cm}$ Sirtukelas A (CBR 70). Bentuktikungan PI 01 Full-Circle, dan PI 02 Full-Circle. Biaya yang diperlukan adalah sebesar Rp 14.745.341.000,-.
\end{abstract}

Kata Kunci : $\quad$ Geometrik, Metode Analisa Komponen, PerkerasanLentur, Rencana Anggaran Biaya. 


\section{PENDAHULUAN}

Untuk menunjang pembangunan prasarana kota dan industri yang dikerjakan Pemerintah Provinsi Jawa Timur melalui Dinas Pekerjaan Umum Bina Marga Propinsi Jawa Timur, maka dilaksanakan proyek peningkatan jalan untuk menunjang kelancaran pembangunan dan perekonomian khususnya di wilayah Legundi - Bunder.

Namun ruas jalan yang kurang memadai untuk perkembangan lalu lintas saat ini, dan kondisi jalan yang retak - retak, berlubang, serta bergelombang, menjadi masalah yang cukup mengganggu bagi pengguna jalan jurusan Legundi - Bunder.

Dari latar belakang tersebut penulis mencoba untuk meninjau dan merencanakan kembali proyek peningkatan jalan tersebut sebagaimana perencanaan jalan baru dengan tujuan untuk bias dijadikan sebagai alternative acuan dalam perencanaan geometrik[1][2][3], tebal perkerasan [4][5][6] maupun perencanaan anggaran biaya dalam perencanaan jalan yang dituangkan dalam suatu Tugas Akhir dengan judul"AAnalisa Tebal Perkerasan Lentur Pada Rencana Peningkatan Jalan Pada Ruas Legundi - Pertigaan Bunder KM.5 + 700 s/d 13 + 700 STA. $0+000$ - 4+000“.

\section{METODE PENELITIAN}

\subsection{Lokasi Penelitian.}

Penelitian ini dilakukan di Laboratorium Teknik Sipil Universitas Kadiri, pada awal bulan maret dan selesai pada bulan juni dengan menggunakan metode Eksperimen.

\subsection{Alur Penelitian}

Data yang dibutuhkan untuk perencanaan ini yaitu data sekunder yang diperoleh dari instansi terkait, data sekunder yang dimaksud adalah:Data Perencanaan Geometrik meliputi Peta Lokasi Proyek,Topografi Lokasi Proyek, Data Perencanaan Perkerasan Lentur meliputi Data Teknis Jalan,Data CBR,Data Lalu Lintas,Data Curah Hujan Data Perhitungan Anggaran Biaya meliputi Harga Satuan Dasar Upah, Bahan dan Alat,Harga Satuan Pekerjaan (HSP)[7][8][9].

Data - data yang telah didapat selanjutnya diolah.Langkah - langkah yang dilakukan dalam tahapan pengolahan data yaitu: Pengolahan data CBR tanah.analisa tanah dasar dilakukan untuk mengetahui daya dukung tanah dasar karena mutu dan daya tahan suatu konstruksi perkerasan dipengaruhi oleh sifat tanah dasar. Pengolahan data lalu lintas,data lalu lintas yang berupa LHR dianalisa untuk mendapatkan tingkat pertumbuhan kendaraan baik pertumbuhan rata-rata maupun pertumbuhan tiap jenis kendaraan sampai dengan akhir umur rencana.Pengolahan data perkerasan jalan,data yang telah didapatkan untuk pengolahan ini bertujuan untuk menentukan atau merencanakan tebal perkerasan lentur yang digunakan dalam perencanaan tersebut. Penentuan 
Harga Satuan,harga satuan dihitung untuk semua kegiatan konstruksi dan pemeliharaan, dengan menggunakan dan menyelesaikan lembar-lembar kerja [10][11][12]. Penentuan Volume Pekerjaan,dari hasil perencanaan, gambar dan pengukuran kita dapat menentukan volume pekerjaan[13][14][15]. Data yang telah didapatkan untuk pengolahan ini bertujuan untuk menentukan tebal perkerasan yang digunakan dalam perencanaan tersebut. Dalam hal ini untuk menghitung perencanaan perkerasan menggunakan Metode Analisa Komponen (MAK) [16][17].

\section{HASIL DAN PEMBAHASAN}

\subsection{Data Teknis Jalan}

Nama Jalan $\quad$ : Legundi - PertigaanBunder KM. $5+700$ s/d $13+700$ STA. 0+000 s/d 4+000

TipeJalan $\quad: 2 / 2$ TB (dua lajur dua arah tidak terbagi)

BahuJalan : Ada $(2 \times 2 \mathrm{~m})$

Panjang / Lebar : 7,5 M / $\pm 4 \mathrm{KM}$

Kelas Jalan : IIIA

FungsiJalan : Kolektor Primer

\subsection{Dasar - Dasar Perhitungan Perkerasan Lentur}

Perhitungan tebal perkerasan lentur menggunakan Metode Analisa Komponen Bina Marga

SKBI-2.3.26.1987/UDC 625.73 (02)[18][19] dengan ketentuan sebagai berikut:

Umur Rencana (UR)

: 10 tahun

Pertumbuhan Lalu Lintas (i) : :6\%

Jalan dibuka tahun : : 2019

CBR tanah dasar $\quad: 4,27 \%$

Curah Hujan $\quad: 1787 \mathrm{~mm} / \mathrm{th}$

\subsection{Perhitungan Alinyemen Horisontal}

Perhitungan geometric pada alinyemen horizontal meliputi:

\subsubsection{Data dan ketentuan}

Kelas jalan $=$ Kolektor kelas II

Kecepatan rencana, $\mathrm{Vr}=80 \mathrm{~km} / \mathrm{jam}$

Lebar lajur ideal untuk jalan kelas II $=3.75 \mathrm{~m}$

Tipe jalan direncanakan 2 lajur 2 arah tidak terbagi

$\mathrm{R} \min =\frac{\mathrm{Vr}^{2}}{127\left(\mathrm{e} \mathrm{maks}_{\mathrm{f} \text { maks })}\right.}$ 
Untuk Vr 120 km/jam, maka Rmin = 209,974 m

Rmin $=210$ m dengan nilai e maks $=0.1[20]$

\subsubsection{Perhitungan Tikungan Horisontal}

PI 01 menggunakan tikungan jenis Full Circle dengan Rmin 209,974 $\mathrm{m} \rightarrow$ diambil $\mathrm{R}=$ $900 \mathrm{~m}$

$$
\begin{aligned}
\mathrm{Vr} & =80 \mathrm{~km} / \mathrm{jam} \\
\Delta & =5,033^{\circ} \\
\mathrm{Rc} & =900 \mathrm{~m} \ldots \ldots \ldots . . \text { direncanakan } \\
\mathrm{Tc} & =\operatorname{Rc} \tan 1 / 2 \Delta \\
& =900 \tan 1 / 25,033^{\circ} \\
& =39,555 \mathrm{~m}
\end{aligned}
$$

$$
\begin{aligned}
\mathrm{Ec} \quad & =\mathrm{Tc} \tan 1 / 4 \Delta \\
& =39,555 \tan 1 / 45,033 \mathrm{o} \\
& =0,868 \mathrm{~m} \\
& \mathrm{Lc} \quad=\frac{\Delta 2 \pi \mathrm{Rc}}{360} \\
= & \frac{5,033 \cdot 2 \cdot \pi 900}{360} \\
& =79,058 \mathrm{~m}
\end{aligned}
$$

PI 02 menggunakan tikungan jenis Full Circle dengan Rmin 209,974 $\mathrm{m} \rightarrow$ diambil $\mathrm{R}=900$

$\mathrm{m}$

$$
\begin{array}{ll}
\mathrm{Vr} & =80 \mathrm{~km} / \mathrm{jam} \\
\Delta & =9,267^{\circ} \\
\mathrm{Rc} & =900 \mathrm{~m} \ldots \ldots \ldots . . \text { direncanakan } \\
\mathrm{Tc} & =\operatorname{Rc} \tan 1 / 2 \Delta \\
& =900 \tan 1 / 29,267^{\circ} \\
& =72,94 \mathrm{~m}
\end{array}
$$

$$
\begin{aligned}
\mathrm{Ec} & =\mathrm{Tc} \tan 1 / 4 \Delta \\
& =72,94 \tan 1 / 49,267 \mathrm{o} \\
& =2,951 \mathrm{~m} \\
\mathrm{Lc} & =\frac{\Delta 2 \pi \mathrm{Rc}}{360} \\
& =\frac{9,267.2 \cdot \pi 900}{360} \\
& =145,565 \mathrm{~m}
\end{aligned}
$$

Kontrol hitungan Tc PI $01+$ Tc PI 02

$$
=39,555+72,94=112,495 \mathrm{~m}
$$

$\mathrm{D}_{\mathrm{PI} 01 \text { - PI } 02}=2413,875 \mathrm{~m}$

Kontrol hitungan Tc PI $01+$ Tc PI $02<$ D PI 01 - PI 02

\subsubsection{Perhitungan Kelandaian}

Contoh perhitungan kelandaian g ( A - PVI1)

Elevasi Awal

$$
\begin{array}{lll}
=32,00 \mathrm{~m} & \text { STA Awal } & =0+000 \\
=32,00 \mathrm{~m} & \text { STA PVI } & =0+500
\end{array}
$$

Elevasi PVI1

$g 1=\frac{32-32}{500} \times 100 \%=0 \%$

Untuk perhitungan selanjutnya disajikan dalam tabel berikut:

Tabel 1.Data Titik PVI

\begin{tabular}{|l|l|l|l|l|l|}
\hline No. & Titik & Sta & Elevasi & Jarak & Kelandaian \\
\hline
\end{tabular}




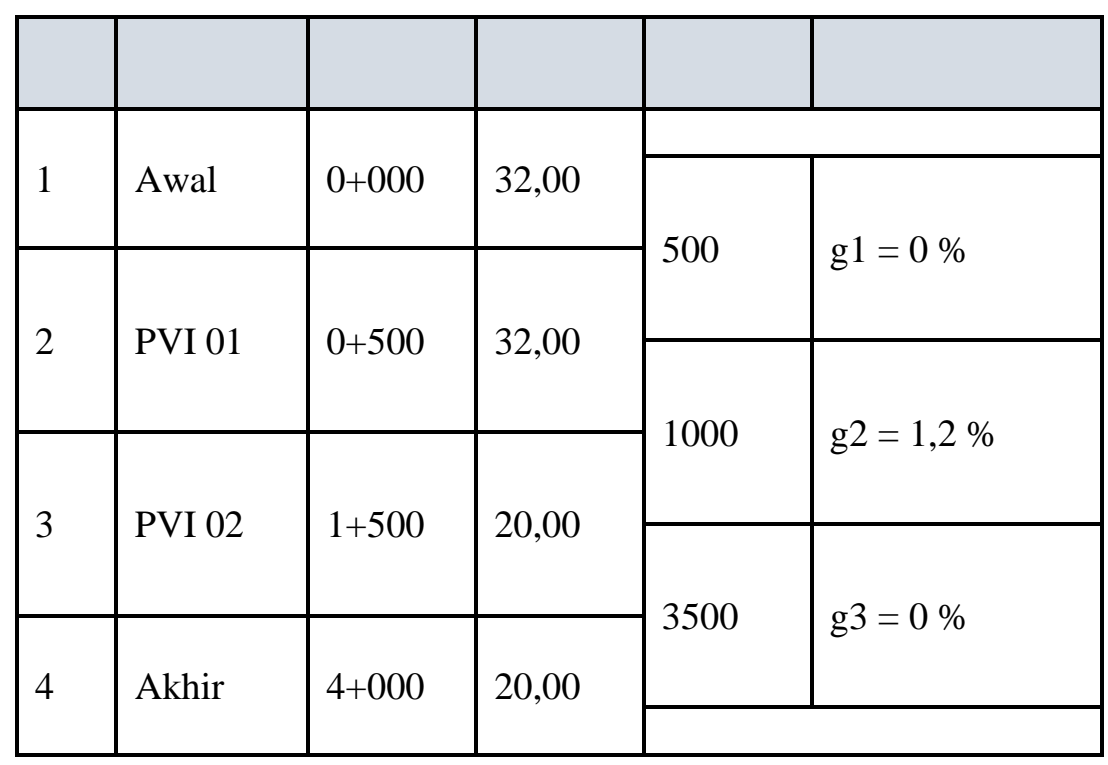

Sumber: Perhitungan Tebal Perkerasan Lentur

\subsubsection{Penghitungan Lengkung Vertikal}

a) PVI 01

1. Data-data :

Stationing PVI $01=0+500$

Elevasi PVI $01=32,00 \mathrm{~m}$

$\mathrm{Vr} \quad=80 \mathrm{~km} / \mathrm{jam}$

$\mathrm{g} 1=0 \%$

$\mathrm{g} 2=1,2 \%$

$A=\left[g_{2}-g_{1}\right]$

$=[1,2 \%-0 \%]$

$=-1,2 \%$ (lengkung Cembung)

2. Jarak Pandang Henti (Jh)

Dari tabel Jh minimum yang digunakan adalah $120 \mathrm{~m}$.

3. Panjang lengkung vertikal

a. Pengurangan goncangan

$$
\begin{aligned}
& L_{v}=\frac{V r^{2} \times A}{360} \\
& =\frac{210^{2} \times 1,2}{360} \\
& =147 \mathrm{~m}
\end{aligned}
$$

Diambil Lv terbesar, yaitu $=147 \mathrm{~m}$

Karena $\mathrm{Jh}<\mathrm{Lv}=120 \mathrm{~m}<147 \mathrm{~m}$ (ok)

b) PVI 02 
1. Data - data :

Stationing PVI $02=1+500$

Elevasi PVI $02=20,00 \mathrm{~m}$

$\mathrm{Vr} \quad=80 \mathrm{~km} / \mathrm{jam}$

$\mathrm{g} 2=1,2 \%$

$\mathrm{g} 3=0 \%$

$A=\left[g_{3}-g_{2}\right]$

$=[1,2 \%-0 \%]$

$=1,2 \%$ (lengkung cekung)

1. Jarak Pandang Henti (Jh)

Dari tabel Jh minimum yang digunakan adalah $120 \mathrm{~m}$.

2. Panjang lengkung vertikal

a. Pengurangan goncangan

$L_{v}=\frac{V r^{2} \times A}{360}=\frac{210^{2} \times 1,2}{360}=147 \mathrm{~m}$

Diambil Lv terbesar, yaitu $=147 \mathrm{~m}$

Karena $\mathrm{Jh}>\mathrm{Lv}=120 \mathrm{~m}>147 \mathrm{~m}$

\subsubsection{Perhitungan Lalu Lintas Harian Rata-Rata (LHR)}

Tabel 2.Perhitungan Lalu Lintas Harian Rata-rata awal dan akhir umur rencana

\begin{tabular}{|l|l|l|l|l|l|l|}
\hline JENIS KENDARAAN & i & UR & $\begin{array}{l}\text { LHR } \\
\mathbf{2 0 1 8}\end{array}$ & $\begin{array}{l}\text { LHR } \\
\mathbf{2 0 1 9}\end{array}$ & $\begin{array}{l}\text { LHR } \\
\mathbf{2 0 2 9}\end{array}$ \\
\hline Sedan, Jeep, Station Wagon (1+1) & $6 \%$ & & 1454 & 1541 & 2759 \\
\hline Angkutan penumpang (1+2) & $6 \%$ & & 157 & 166 & 298 \\
\hline Pick Up, Micro Truck (1,5+2,5) & $6 \%$ & \multirow{n}{*}{10} & & 1093 & 1159 & 2075 \\
\cline { 1 - 2 } & $6 \%$ & & 8 & 8 & 14 \\
\hline Bus Kecil (3,5+3,5) & $6 \%$ & & 10 & 11 & 19 \\
\hline Truck Resar (6+7) & $6 \%$ & & 1741 & 1845 & 3305 \\
\hline
\end{tabular}

Sumber: Perhitungan Tebal Perkerasan Lentur

Tabel 3. Perhitungan Lalu Lintas Harian Rata-rata awal dan akhir umur rencana (Lanjutan)

\begin{tabular}{|l|l|l|l|l|l|}
\hline JENIS KENDARAAN & i & UR & $\begin{array}{l}\text { LHR } \\
\mathbf{2 0 1 8}\end{array}$ & $\begin{array}{l}\text { LHR } \\
\mathbf{2 0 1 9}\end{array}$ & $\begin{array}{l}\text { LHR } \\
\mathbf{2 0 2 9}\end{array}$ \\
\hline Truck Sedang 2 Sumbu (5+8) & $6 \%$ & & 451 & 478 & 855 \\
\cline { 1 - 2 } \cline { 5 - 6 } Truck 3 Sumbu (5+10x2) & $6 \%$ & & 325 & 345 & 617 \\
\cline { 1 - 2 }
\end{tabular}




\begin{tabular}{|c|c|c|c|c|}
\hline Truck Gandengan $(5+7,5 \times 7,5)+(5+5)$ & $6 \%$ & 35 & 37 & 66 \\
\hline 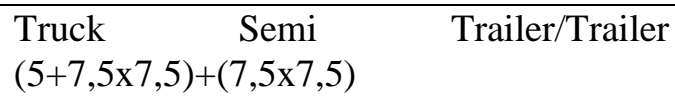 & $6 \%$ & 45 & 47 & 84 \\
\hline \multicolumn{2}{|l|}{ Jumlah Kendaraan/hari/2arah } & 5317 & 5636 & 10093 \\
\hline
\end{tabular}

Sumber: Perhitungan Tebal Perkerasan Lentur

\subsection{Penentuan Daya Dukung Tanah (DDT)}

Menentukan Nilai CBR yang Digunakan :

Yang dimaksud harga CBR disini adalah Nilai CBR laboratorium yang diperoleh sebesar 4,27\%. Menentukan Nilai Daya Dukung Tanah (DDT). DDT $=1,6649+4,3592 \log (\mathrm{CBR})=$ $1,6649+4,3592 \log (4,27 \%)=4,3053$. Nilai DDT yang didapat sebesar 4,3053.

\subsection{Penentuan Faktor Regional (FR)}

Faktor Regional merupakan faktor setempat dimana nilai ini didapat dari table berikut

Tabel 4. Nilai Faktor Regional (FR)

\begin{tabular}{|c|c|c|c|c|c|}
\hline & \multirow{2}{*}{\begin{tabular}{|c|}
$\begin{array}{c}\text { Kelandaian } \\
\text { I }\end{array}$ \\
$\%$ \\
kendaraan \\
berat
\end{tabular}} & \multicolumn{2}{|c|}{$\begin{array}{c}\text { Kelandaian II } \\
(6-10 \%)\end{array}$} & \multicolumn{2}{|c|}{$\begin{array}{c}\text { Kelandaian III } \\
(>10 \%)\end{array}$} \\
\hline & & \multicolumn{2}{|c|}{$\begin{array}{c}\% \text { kendaraan } \\
\text { berat }\end{array}$} & \multicolumn{2}{|c|}{$\begin{array}{c}\% \text { kendaraan } \\
\text { berat }\end{array}$} \\
\hline & \begin{tabular}{|c|c|}
$\leq 30$ & $>30 \%$ \\
$\%$ & $\%$ \\
\end{tabular} & $\leq \mathbf{3 0} \%$ & $>\mathbf{3 0} \%$ & $\leq 30 \%$ & $>\mathbf{3 0} \%$ \\
\hline Iklim I $<900 \mathrm{~mm} / \mathrm{th}$ & $0,5|1,0-1,5|$ & 1,0 & $|1,5-2,0|$ & 1,5 & $2,0-2,5$ \\
\hline Iklim II > $900 \mathrm{~mm} / \mathrm{th}$ & $1,52,0-2,5$ & 2,0 & $2,5-3,0$ & 2,5 & $3,0-3,5$ \\
\hline
\end{tabular}

Perkerasan Lentur Jalan Raya Dengan Metode Analisa Komponen 1987

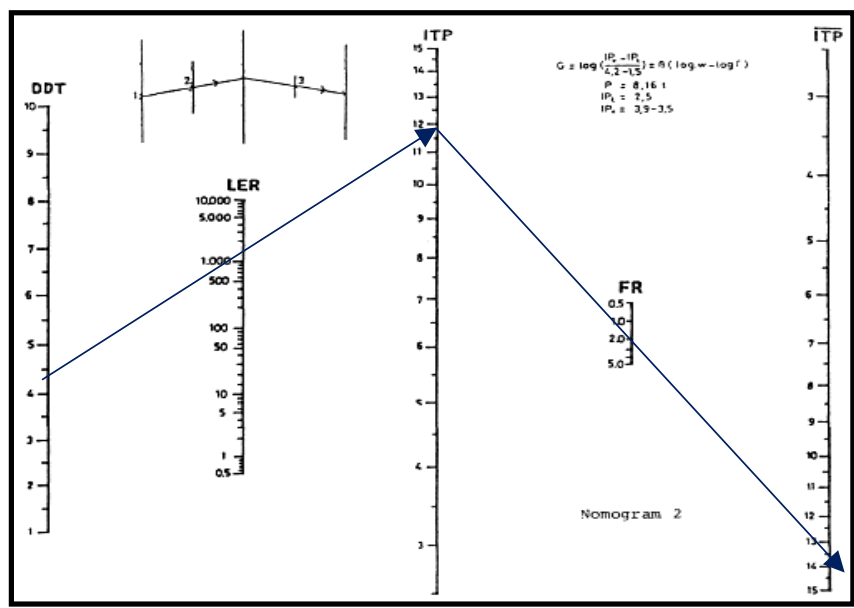


Gambar 1. Nomogram $2(\mathrm{IPt}=2,5$ dan $\mathrm{IPo}=3,9-3.5)$

\subsection{Perencanaan Tebal Perkerasan Lentur}

Dalam perencanaan ini, penulis menggunakan tiga alternatif perencanaan tebal perkerasan lentur agar mendapat komposisi dan tebal perkerasan yang paling efektif. Dari nilai ITP yang telah diketahui maka didapatkan hasil perencanaan perkerasan sebagai berikut:

1) Alternatif Terpilih

- $\mathrm{a} 1=0,40$ (Laston)

- $\quad$ a2 $=0,15$ (Stabilisasi tanah dengan semen/CTB)

- $\quad$ a3 = 0,13 (Sirtu/Pitrun Kelas A)

- $\quad \mathrm{D} 1=10 \mathrm{~cm}$ (Lapis Permukaan)

- $\quad \mathrm{D} 2=20 \mathrm{~cm}$ (Lapis Pondasi)

- $\quad I T P=a 1 \times D 1+a 2 \times D 2+a 3 \times D 3$

$$
13,5=0,40 \times 10+0,15 \times 20+0,13 \times D 3
$$

- $\quad$ D3 $=50$ (Lapis Pondasi Bawah)

\subsection{RekapitulasiRencanaAnggaranBiaya}

Dari hasil perhitungan harga satuan pekerjaan yang telah dilakukan didapatkan biaya total dari pembangunan Jalan RuasLegundi - Pertigaan Bunder sebagaimanaberikut.

3.8.1 Rekapitulasi Anggaran Biaya

\begin{tabular}{|c|c|c|}
\hline NO. & JENIS PEKERJAAN & JUMLAH HARGA \\
\hline I. & PEKERJAAN PERSIAPAN & 394.818.000,- \\
\hline II. & PEKERJAAN TANAH & Rp 1.594.804.245,-- \\
\hline III. & PEKERJAAN PERKERASAN & Rp $11.415 .234 .000,-$ \\
\hline & JUMLAH & Rp 13.404.856.245,- \\
\hline & PPN $10 \%$ & Rp $\quad 1.340 .485 .625,-$ \\
\hline & JUMLAH TOTAL & Rp $14.745 .341 .870,-$ \\
\hline & DIBULATKAN & Rp $14.745 .341 .000,-$ \\
\hline \multicolumn{3}{|c|}{$\begin{array}{l}\text { TERBILANG: "Empat belas miliar tujuh ratus empat puluh lima juta tiga ratus empat } \\
\text { puluh satu ribu rupiah" }\end{array}$} \\
\hline
\end{tabular}

Sumber: Perhitungan Rencana Anggaran Biaya 


\section{KESIMPULAN}

Dari perencanaan dan perhitungan pada bab sebelumnya maka dapat diambil kesimpulan sebagai berikut:

1. Perencanaan tebal perkerasan lentur menggunakan Metode Analisa Komponen SKBI 2.3.26. 1987 didapat sebuah tebal perkerasan untuk Surface laston MS 744 dengan tebal 10 $\mathrm{cm}$, Base CTB dengan tebal $20 \mathrm{~cm}$, dan Subbase sirtu kelas A (CBR 70) dengan tebal 50 $\mathrm{cm}$.

2. Perencanaan geometrik jalan raya pada ruas Legundi - Pertigaan Bunder Km. 5+700 s/d 13+700 Sta. 0+000 s/d 4+000[21] didapat alinyemen horisontal berupa 2 tikungan Full Circle dan didapat 2 alinyemen vertikal yaitu 1 lengkung cekung dan 1 lengkung cembung.

3. Biaya yang dibutuhkan untuk mengerjakan proyek ini dengan menggunakan standar harga dasar dari Dinas Pekerjaan Umum Bina Marga Kelompok IV tahun 2019 maka didapat Anggara Biaya sebesar Rp 14.745.341.000.,- (Empat belas miliar tujuh ratus empat puluh lima juta tiga ratus empat puluh satu ribu rupiah)

\section{SARAN}

Berdasarkan hasil perencanaan ini ada beberapa saran sebagai berikut: Dalam perhitungan perkerasan data yang digunakan harus lengkap agar memudahkan perhitunganperencanaan. Untuk menghasilkan suatu perencanaan yang baik dan benar standar yang digunakan sebagai dasar perhitungan dan perencanaan harus paten sehingga perencanaan terarah dengan mengacu pada standar tersebut. Untuk mendapatkan suatu proyek konstruksi yang tepat waktu, mutu dan biaya sebaiknya pelaksanaan suatu proyek konstruksi harus mempunyai straegi pelaksanaan yang tepat dengan penjadwalan yang baik karena straegi pelaksanaan yang dilakukan akan mempengaruhi waktu pelaksanaan dan anggaran biaya.

\section{UCAPAN TERIMAKASIH}

Dalam penyusunan artikel ini, penulis ucapkan terimakasih kepada dosen pembimbing dan Universitas Kadiri. Penulis berharap agar artikel ini dapat bermanfaat bagi pembaca.

\section{DAFTAR PUSTAKA}

[1] Dinas Pekerjaan Umum Bina Marga, Tata Cara Perencanaan Geometrik Jalan Antar Kota. Jakarta, 1997.

[2] P. R. Nahak, Y. C. S. P, and S. Winarto, "STUDI PERENCANAAN TEBAL PERKERASAN KONSTRUKSI JALAN RAYA PADA RUAS JALAN UMASUKAER DI KABUPATEN MALAKA,” Jurmateks, vol. 2, no. 1, pp. 75-85, 2019.

[3] N. F. A. Sari and H. Widyastuti, "Analisis Kelayakan Ekonomi dan Finansial 
Pembangunan Jalan Tol Pandaan - Malang," J. Tek. ITS, vol. 8, no. 1, 2019, doi: 10.12962/j23373539.v8i1.41495.

[4] Departemen Pekerjaan Umum, "Petunjuk Perencanaan Tebal Perkerasan Lentur Jalan Raya Dengan Metode Analisa Komponen," 1987.

[5] S. Sukirman, Perkerasan Lentur Jalan Raya. Bandung, 1993.

[6] [Kementerian PUPR]. Kementerian Pekerjaan Umum dan Perumahan Rakyat, “Perencanaan Perkerasan Jalan Beton Semen,” p. 52, 2003.

[7] Departeman Pekerjaan Umum Direktorat Jenderal Bina Marga, Panduan Analisa Harga Satuan. Jakarta, 1995.

[8] A. I. Candra, E. Gardjito, Y. Cahyo, and G. A. Prasetyo, "Pemanfaatan Limbah Puntung Rokok Filter Sebagai Bahan Campuran Beton Ringan Berpori," UKaRsT, vol. 3, no. 1, p. 82, 2019, doi: 10.30737/ukarst.v3i1.365.

[9] R. Fitriana, "STUDI KOMPARASI PERENCANAAN TEBAL PERKERASAN KAKU JALAN TOL MENGGUNAKAN METODE BINA MARGA 2002 DAN AASHTO 1993 ( Studi Kasus : Ruas Jalan Tol Solo - Kertosono ),” J. Chem. Inf. Model., vol. 53, no. 9, pp. 1689-1699, 2013, doi: 10.1017/CBO9781107415324.004.

[10] I. D. Husodo, Manajemen Proyek Dan Konstruksi Jilid 1. Jakarta, 1995.

[11] A. I. Candra, A. Yusuf, and A. R. F, "Studi Analisis Daya Dukung Pondasi Tiang Pada Pembangunan Gedung Lp3M Universitas Kadiri,” J. CIVILA, vol. 3, no. 2, p. 166, 2018, doi: $10.30736 /$ cvl.v3i2.259.

[12] Supriadi, Y. C. S. P, A. Ridwan, and A. I. Candra, "PENELITIAN PENAMBAHAN BAHAN BATU PADAS PADA CAMPURAN ASPAL BETON," Jurmateks, vol. 2, no. 1, pp. 154-163, 2019.

[13] A. Gunarto and A. I. Candra, "Penelitian Campuran Aspal Beton Dengan Menggunakan Filler Bunga Pinus," UKaRsT, vol. 3, no. 1, p. 37, 2019, doi: 10.30737/ukarst.v3i1.351.

[14] Direktorat Jendral Bina Marga, "Tata Cara Perencanaan Geometrik Jalan Antar Kota." 2017.

[15] B. A. Harsono, S. Winarto, and Y. C. S, "PERENCANAAN PENINGKATAN JALAN PADA RUAS JALAN PACITAN-NGADIROJO,”Jurmateks, vol. 1, no. 2, pp. 291-302, 2018.

[16] Departemen Pekerjaan Umum, Metode AASTHO 1972. Jakarta: Yayasan Badan Penerbit PU, 1972.

[17] R. Hidayah, A. Ridwan, and Y. C. S. P, "ANALISA PERBANDINGAN MANAJEMEN WAKTU ANTARA PERENCANAAN DAN PELAKSANAAN,"Jurmateks, vol. 1, no. 2, pp. 281-290, 2018. 
[18] Didik Purwadi, Buku Ajar Perkerasan Jalan. Semarang, 2008.

[19] [Kementerian PUPR]. Kementerian Pekerjaan Umum dan Perumahan Rakyat direktorat jendral bina marga and D. J. B. Marga, "Manual Desain Perkerasan Jalan," Nomor 02/M/BM/2013, 2013.

[20] Dinas Pekerjaan Umum Direktorat Jenderal Bina Marga, Manual Perkerasan Jalan Dengan Alat Benkelmen Beam No. 01/MN/BM/83. Jakarta: Yayasan Badan Penerbit PU, 1983. 